\title{
Globalization and Education: Perspectives in Knowledge Production and Utilization
}

\author{
Gbenga S. Adejare \\ ORCID iD: https://orcid.org/0000-0003-1893-6328
}

Olayinka Akanle

ORCID iD: https://orcid.org/0000-0002-4707-4491

Vera E. Abaimu

ORCID iD: https://orcid.org/0000-0001-5186-0260

\begin{abstract}
One historical process and current that has defined knowledge production and utilization like globalization does not exist. Globalization, while it has affected every component of human existence, has impacted much more in the area of education. Globalization affects what is known, how it is known and taught, how it is inculcated in people across generations, how it is utilized, how it is validated and how it is perpetuated. The existential realities across disciplines all over the world, and particularly in Africa, clearly demonstrate that globalization continues to be relevant in understanding the ramifications of education across space and time. This article contributes to knowledge relative to the interface of globalization and education against the strategic background of disciplinary knowledge production and utilization particularly in Africa.
\end{abstract}

Keywords: Education and Knowledge in Africa, Globalisation and Cultural production, Political economy of education. 


\section{Introduction}

Globalisation is a fundamental historical and contemporary forceful reality. Although globalization is not an entirely new social reality, its impacts on human existence across time and places continue to resonate to the extent that there is continued necessity to interrogate not only its existence but continued impacts on the social and institutional realities of the $21^{\text {st }}$ century and beyond. While impacts of globalization are easily noticed in social media, family, industry, economy, politics, etc. (Akanle 2015; Akanle 2012), the covert and overt effectual consequences on education, particularly in knowledge production and utilization need more dedicated examination. This is particularly so as education and knowledge systems are the core drivers and consequential nuclei of globalization as history and current. This is particularly so relative to disciplinary bounds and trajectories as it is the case in Sociology. While Sociology as a discipline is in itself a product of globalization from emergence and rise to prominence, its subfields like Development and Clinical Sociology are themselves products and outcomes of globalization.

What is taught in Sociology and its areas of specialization, how it is taught, what is researched, how it is researched, how it is validated, how it is certified, who certifies it, why and where it is certified, where it is taught, and how and where it is perpetuated are all traceable to impacts and ramifications of globalization. Hence, how and where knowledge, like research processes, findings and outcomes, are executed and disseminated as scholarly publications, for example, are all determined and continued to be moderated by forces of globalization (Brankovic, Ringel \& Werron 2018). In fact, the very idea of ranking journals as Scopus journals, International Bibliography of Social Sciences (IBSS) Journals, International Social Science Index (ISI) journals, the Department of Higher Education and Training (DHET) in South Africa, journals, etc., are all efforts towards global competitiveness and outcomes of globalization.

Sociologists and every other scholar are thus conditioned ab initio to think, frame, teach, research and produce knowledge within certain globalization frameworks to be considered globally competitive and acknowledgeable internationally and locally. Requirements for global and local tenure, fellowships, grants, ratings - like the National Research Foundation (NRF) ratings in South Africa - are all global parameters to drive academic and disciplinary competitiveness but these are not without implications as people 
now tend to continually look more externally in education and knowledge production than internally, even when internal issues remain gargantuan and massive, needing glocal and sometimes outrightly local attention and solutions. While these rankings encourage competition positively, they sometimes stifle contextual and local interventions and solutions that are important (Connell 2007). Hence, these rankings and other globalization induced and enforced education and knowledge approaches to drive global relevance and competitiveness particularly make decolonial disciplinary ingenuities and creativities, original social thoughts and knowledge amplifications, contextual knowledge processes utilizations and research and applications adoption very difficult (Wedlin 2014; Connell 2013).

Globalization is the main reason curricula and syllabi are standardized to be globally competitive. This is particularly so in subfields like Clinical Sociology, which share huge professional, academic, practice, epistemological and ontological boundaries with core and medical sciences. The practice is very centralized and formalized. Unlike other areas of Sociology and Social Sciences where Africology, Africentricism, Africanism and decolonization efforts are free styling in methodology, this is not readily the case in Clinical Sociology. Broadly speaking, the core of Sociology units is moderated and driven in knowledge production by globalization. Furthermore, since aggressive globalization has not abated and continually efficacious across education frontiers, it is thus very important to engage elements of globalization especially in education and remits of knowledge. It is only when these epistemic engagements and pragmatic intellectualism are consciously and continually engaged that education, knowledge production and utilization can be systemically sustainable and beneficial globally, and particularly in Africa.

\section{Engaging Globalization: Meanings and Ramifications}

Scholarship and research on globalization are large and very expansive. Literature and data on the subject are also burgeoning without any sign of receding. This is because ramifications, trajectories and outcomes of globalization appear unendingly with huge impacts on individual, group, national, continental and global survival. Over time, culture, technology, polity, ecosystem and economy, among others, have continued to be under the influence of globalization. Education - knowledge production and utilization 
are critically affected by globalization as knowledge systems - production, dissemination and consumption/utilization. Unfortunately, impacts of globalization on education is more noteworthy because of its intergenerational consequences. Education connects the present to distant future in unique manners. What is taught to the current generation will determine the future of future generations. It is therefore noteworthy that globalization have uniquely important angles on education necessitating continuous interrogation. While academic writings on globalisation have constantly deepened in the past and its elements were long seen in various intergroup relations and tractions of ancient cities and communities, current studies need to engage recent manifestations across social institutions and education is key.

Globalisation is conceptualised better in context rather than defined. Globalisation is the process of making the tangible or intangible events, persons, behaviours, beliefs, identities and other social, geographical, ecopolitical and economic phenomenon seamlessly impactful and felt across the world (McMillan, Rodrik \& Verduzco-Gallo 2014; Mohan \& ZackWilliams 2002). Globalization facilitates the easy spread of social realities in manners akin profound social relation in village setting metaphorically speaking and the developed countries of the West/North are the epicentres of globalization. They are usually the drivers and moderators of globalization while Africa and other underdeveloped components of the world only largely consume products and consequences of globalization as observable in the education, knowledge production, and global warming.

Working from below, it is possible to observe that, in reality, nothing can be global or globalized without first being local. By this, it means that there is certainly an origin or source through which any idea or phenomenon that is globalising or globalised can be referenced or traced. The proliferation of fast food around the globe has its origins in modern western societies (Olutayo \& Akanle 2009). In 1886, John Pemberton originated a fizzy drink popularly known as Coca-Cola in America, which has now become a global brand with its presence in over 200 countries of the world (Encyclopaedia Britannica 2018; Olutayo \& Akanle 2009).

Similarly, political ideologies such as communism and democracy, even having been embraced by different countries of the world, can be traced to certain origins. This is also true of wholesale economic ideologies, like capitalism and socialism, now globalized around the world. It is, however, important to note that, more often than not, global power dynamics determine 
which knowledge eventually globalizes and whether or not the original source of the knowledge will be profoundly acknowledged. When ideas, like in education and disciplines, originate from the South, it may not globalize, compared to when it is from the educationally powerful North. Cases abound in education and scholarship, but a relevant case in point is that of adducing origin of Sociology to the West and western scholars like Auguste Comte rather than Africa and Ibn Khaldun ${ }^{1}$ who used Al-Umran to conceptualize Sociology much earlier (Alatas 2014; Arazeem \& Salawu 2012; Alatas 2006: Danermark et al. 2002; Dhaouadi 1990; Hadden 1997).

As globalisation occurs, cultural exchanges, economic transactions, political trade-offs and geographic and intellectual/educational encroachments become inevitable. Often, globalization operates and penetrates as diffusion and acculturation. In more contemporary terms, globalization operates more as acculturation in Africa. This is as Africa's values and knowledge systems are annihilated and swallowed up large scale. This is especially so in formal education as observable in courses including in Sociology and, more specifically, Clinical Sociology. African indigenous knowledge systems are hardly included, taught and propagated in disciplines and courses are dominated by western thoughts, contents and knowledge. Even when local African knowledge systems are infused into courses, they are as tokenisms, with little intellectual seriousness and utilization (Omobowale \& Akanle 2017). As such, powerful economies and knowledge hubs of the world dominate the weaker ones within globalization systems. Continents and countries at the receiving end (weaker ones like Africa) thus constantly practise and transmit or transfer globalized/largely foreign socio-political values from one place to another and from one generation to another. Inadvertently, the ability of the states or the societies that are experiencing globalisation would eventually determine whether or not globalisation processes will promote or demote original knowledge indigenous to these countries and countries. What then would happen in countries and continents, like Africa, with weak abilities in global political economy of education particularly relative to knowledge production and utilization now and in the future?

Membership of international bodies and consent/assent to global pacts impact national sovereignties, but also strengthen or weaken the economy,

\footnotetext{
${ }^{1}$ Ibn Khaldun (732-808 AH/1332-1406). He was a social thinker born in Tunis in $1332 \mathrm{AD}$.
} 
polity and other aspects of life of a people as globalisation occurs. For instance, member countries of the World Health Organisation (WHO), United Nations (UN), the Bretton Wood or the World Bank (WB) and World Trade Organisation (WTO), amongst others, are constrained by certain treaties that may undermine, or at least interfere with their local policies and programmes. However, in most cases, the economic buoyant and politically powerful nations influence other member states to either amend old treaties or enact new ones to their own favour. Unfortunately, most countries in Africa are largely poor and socio-economically weak. This makes their membership or presence in these global entities merely symbolic and sometimes disadvantageous, since their capacities for influencing the trend of events and policies in the world are minimal, if not completely absent. Fast-paced, globalisation processes are driven by a number of things. Chief among these are the mass media, technology and multinational corporations (MNCs). Through these drivers, infusion and diffusion of economic, cultural, political values and educational as well as knowledge systems are perpetrated, contracted, enhanced and perpetuated.

\section{Theoretical and Practical Issues in Globalisation}

It is possible to categorize theories in globalization studies along two major approaches. These are the hyperglobalist and the transformationist. According to Zoran (2008), globalization theories are generally very propulsive area of research and need more continuous engagements. For the hyperglobalist approach, it conceives globalization as an irrepressible legitimate process of global development based on the principle of market operation and supranational institution. This leads to advancement in the level of civilisation, not necessarily tied to historical antecedents. Within the hyperglobalist perspective, global system has an internal logic/mechanism for self-regulation and adaption across borderlines. However, this approach is often seen as too deterministic and ahistorical. For Anthony Giddens and Immanuel Wallerstein, etc., who are main theoretical figures and frontliners in globalization and it is highly transformative as a ubiquitous process. This is to the extent that no country and continent are immune to the effects and occurrences of globalization, particularly in the age of Information Technologies, the internet and social media. Globalization transforms societies; it is in contact with either heterogeneity or homogeneity of cultural processes, social relations and/ or educational systems. However, the tendencies are towards cultural 
homogeneity even though hybridity and heterogeneity are possible and are more sustainable.

This theoretical strand links the ubiquity of globalisation processes to the fundamental changes in the organisation of modern society through increasing acceleration of socio-economic dynamics as a result of compression of space and time (Zoran 2008). What the transformationists have successfully done was to appropriate the forces of modern space - capitalism, politics, industrialisation and militarism - to explain the ubiquity of globalisation. A major criticism levelled against this approach is the failure to properly interrogate the unintended consequences of modernity which have made people to crave sustainable (or better still, humane) globalisation processes. The Cultural Theory of globalization opines that globalization can be theorized and accounted for within two major orientations - Cultural Diversity Theory (CDT) and Cultural Homogeneity Theory (CHT). CDT refers to the proliferation of diverse cultural practices and traits in society as a result of the interconnection of people across different borderlines. For instance, it is a commonplace to find different dishes in typically classic African parties, especially in urban spaces. Cultural Homogeneity Theory (CHT) contrasts the claim that globalisation promotes cultural diversity. The major argument here is that universal or similar culture tends to emerge over time as a result of the mixing and meeting of different cultures. This radical perspective draws attention to how various aspects of a culture (take language, for example) suffers or stands a chance of becoming extinct as people embrace new cultures they interact with. This perhaps explains why the ascendancy of English and French languages as official language in many African countries continues to sound the death knell for the survival of many indigenous languages on the continent. On the other hand, cultural globalisation has the possibility to further be accounted for in terms Coca-colonisation and McDonaldisation of the world (Ritzer \& Stepnisky 2014; Idyorough 2002; Lechner 2001). By Cocacolonisation, Transnational Corporations like Coca-Cola and MacDonald's develop global consumerism and culture that are becoming culturally akin to those of the North and this is also observable in the education and knowledge systems across continents including Africa. Generally, the successful global marketing strategies and franchises deployed to create the identical homogenous consumerism around the world are also observable in the homogenization and standardization in the education and knowledge systems.

Drivers of globalization in Africa and across the world include techno- 
logy, social media, internet, global economic institutions, international institutions/ multilateral organizations and global political organization (Daramola \& Oyinade 2015; Mohan \& Zack-Williams 2002). Technology is at the forefront of drivers of globalization. Every other driver of globalization relies on the widespread and deep penetrativeness of globalization to be impactful. Technology enables global access to Africa and opens up the world to Africa. Unfortunately, the poorly regulated and often abused virtual technological contexts have increasingly make ill-prepared and poorly enabled Africa vulnerable in the digital and global space. Africa benefits less than it loses in the globalization marketplace, particularly in knowledge production and utilization. For instance, all the technologies consumed at the global space are produced outside Africa. Yet, these technologies are consumed wholesale in Africa and these technologies determine outcomes of globalization on continents in economic, social and educational terms. Oni (2015) claims that globalisation through improved technology such as telecommunication allows foan increase in capital flow. This broadens the gap between advanced capitalist countries that who determine the tune and the third-world countries, especially in Africa.

According to Daramola and Oyinade (2015) and Mohan and ZackWilliams (2002), globalisation has enabled migration and Africans can easily move within and outside the continent. This has, however, enabled both gains and losses in terms of remittances, brain-drain and remittances (Akanle \& Adesina 2017a; Akanle \& Adesina 2017b; Tebeje 2016). Mass media drives the ubiquity of globalisation processes in Africa, as can be seen in the interaction of local and global media. However, Northern media like CNN, Fox and $\mathrm{BCC}$ determine the dynamics of which information is globalized and to whose advantage - the CNN Effect. Beyond the traditional print and electronic media, social media is driving global information contents and gateways. These social media continually evolve every day. Popular ones include; Facebook, WhatsApp, Twitter, Instagram, e-mails, etc. They bring information from local to global and from global to local in real terms. Their penetrations and reaches are massive and without borders. The level to which people now trust them for knowledge is huge.

Unfortunately, Africa does not own and does not control these social media platforms. Information there are usually tilted against Africa and positive information about Africa are frequently viewed with massive scepticism and frequently discredited by non-Africans and, regrettably, even 
by Africans themselves. A lot of information in the media cause huge damage to the survival of African culture (Daramola \& Oyinade 2015; Surugiu \& Surugiu 2015; Pekarskiene \& Susniene 2014; Zahid 2014; Ezenweke \& Nwadialor 2013; Kanu 2013; Makinde 2013; Onyango 2013; Lee, Yach \& Kamradt-Scott 2011; Arowolo 2010; Abdi 2010; Jones 2010; Madukwe \& Madukwe 2010; Chopra 2004; Kuruk 2002). According to Arowolo (2010), this huge damage can be best described as creating cultural, health, religious, political and economic gaps in the African society as it distorts and reduces the pace of Africa's growth, development and trends. This is especially so in education and knowledge production and utilization in Africa.

\section{Globalisation and Politics in Africa}

There is certainly no country in Africa that has not experienced the impact of globalisation in Africa particularly in the political systems. From Malawi, to Guinea, to Zimbabwe, to South Africa, to Morocco, to Angola or to Madagascar, globalisation has been having myriad of impacts on African political systems. While in precolonial Africa, politics were very indigenously based on the traditional existential needs of Africans, this is no longer the case starting from colonial Africa, apartheid South Africa and post-colonial African political systems. Starting from the colonial era, a major political incursion of globalisation was democracy, even when the democracy was largely antithetical to African indigenous political systems. The degree of unison between the political systems occasioned by globalisation and the traditional systems were very little, to the extent that these foisted political, systems-engendered violence and conflicts across Africa. Cases of these are numerous but include the Mau Mau Movement and Aba Women Riots.

Nigeria's political globalisation presents a good case study from the foregoing and can be seen from the country's colonisation experience by Britain. Various tribes and ethnic groups categorised into two protectorates were forcefully merged to form one country. This amalgamation of the two Protectorates (Northern and Southern Protectorates) by Lord Luggard in 1914 marked the beginning of Nigeria as one entity. The amalgamation failed to take into consideration the diversity and cultural backgrounds of the protectorates. This began the Nigerian political instability the country has been experiencing over these decades (Makinde 2013; Ugbam, Chukwu \& Ogbo 2014). Previously in pre-colonial societies, political positions were held by heredity, 
integrity and popularity. The political head was usually the king who is called 'Oba' in South-Western Nigeria, 'Eze' in the South-East and 'Emir' and other tribes took their linguistic names for their political leader. Presently, Nigeria has been practising the presidential system of government since 1960, which is expensive to maintain (Madukwe \& Madukwe 2010). Conteh-Morgan (2006) argues that globalisation through Western civilisation, a foreign entity, has disorganised traditional institutions that where the custodians of the political culture. This has created traumatisation for individuals, societies and ethnic groups, removing their sense of social security. Foreign entities (Western civilisation) began to dominate and control power over local territorial sovereignty. Other adverse effects of globalisation on Africa's politics may include (1) Violence: various societies attempted resisting colonial domination and control of their political systems such as Ashante resistance to foreign rule, king Nana of Its Ekiri, the Benin massacre in 1897, Nigeria civil war in 1967 and various army coup across Africa countries; (2) Failure of government to provide social services such as education, health, water, housing, etc. This causes lack of trust in government and political tension; (3) Economic restructuring imposed on poorer countries which causes strife, wider inequalities, protests, violent demonstration and conflict; (4) Corruption by government as cash flow and investments can easily be transferred to foreign accounts; (5) Creation of free trade zones that kills local market and makes labour and human rights non-existent; and (6) Increasing situations of intense conflict on the African continent, for instance, civil war in Sierra Leone, military Coups in Ivory coast, etc. Daramola and Oyinade (2015) explain that this presidential system ideology has paved the way for embezzlement and certain level of immunities from prosecution for political leaders. For instance, Daramola and Oyinade (2015) argue that over $\$ 380$ billion has been stolen from Nigeria by various government officials since independence in 1960.

\section{Conclusion}

Globalization is central to the understanding and appreciation of the state and prospect of education and knowledge system of Africa now and the future. Unfortunately, Africa is currently underperforming and remains negatively affected and influenced in the global scheme of things. Furthermore, the role of globalization is huge in keeping the continent in this state. The United Nations' World Economic Situation and Prospect 2020 report confirms that 
'although progress has been achieved in global terms (global terms emphasised), the number of people living in extreme poverty has risen in several sub-Saharan African countries (another point for emphasis)' (United Nations 2020: xi). The apparent contradiction is that growth and development seem to be happening at the same time to different countries fettered by globalisation: global riches flowing unequally to the global West, while global poverty are either caused by or attributed to the global South. This mounting disequilibrium permeates virtually all facets of life - from culture to economy, politics, ecosystem, health, security, industrialisation, education and trade, amongst others.

Significantly, Africa has a lot to do for itself, both to be globally relevant and to continentally useful to its people. The continent also has a lot to do for itself to be salvaged from the negative fallout of globalization and education and knowledge system. Disciplines and sub-disciplines, including Sociology and Clinical Sociology, must acknowledge and manage the complicated roles and impacts of globalization now and going forward. Until Africa begins to significantly influence and play active roles in the process of globalization, globalization will continue to be counter-productive for the education, knowledge systems and education on the continent.

\section{References}

Abdi, A.A. 2010. Globalization, Culture and Development: Perspectives on Africa. Journal of Alternative Perspectives in the Social Sciences 2,1: 1 26.

Akanle, O. 2011a. Nigerian Culture and Identity in a Globalised World. Youth and Nigeria's Intangible Cultural Heritage. Human Development Initiatives (HDI) $28-44$.

Akanle, O. 2011b. Post-Colonial Nation Building, Global Governance, Globalization, and Development in Nigeria and Africa. Africa Insight 41,3: 1-15.

Akanle, O. 2012. The Ligaments of Culture and Development in Nigeria. International Journal of Applied Sociology 2,3: 16 - 21.

Akanle, O. 2015. Culture, Cultural Diversity and Economic Growth in Nigeria and ECOWAS. In Koffi, S.K., J.O. Igue \& O.S. Akande (eds.): Growth and Development in West Africa. ECOWAS Commission. Saarbrücken: LAP Lambert Academic Publishing. 
Akanle, O. \& J.O. Adesina 2017a. International Migrants' Remittances and Kinship Networks in Nigeria: The Flip-side Consequences. Journal of Anthropological Research 73,1: 66 - 91. https://doi.org/10.1086/690609 Akanle, O. \& J.O. Adesina 2017b. Remittances and Household Welfare in Nigeria. African Population Studies 31,7: 3194 - 3211.

https://doi.org/10.11564/31-1-953

Alatas, S.F. 2006. Ibn Khaldūn and Contemporary Sociology. International Sociology 21,6: 782 - 795. https://doi.org/10.1177/0268580906067790

Alatas, S.F. 2014. Applying Ibn Khaldun: The Recovery of a Lost Tradition in Sociology. Abingdon, Oxon: Routledge.

https://doi.org/10.2139/ssrn.2650444

Arazeem, A. \& B. Salawu 2012. Ibn Khaldun: A Forgotten Sociologist. South African Review of Sociology 43,3: $24-40$.

https://doi.org/10.1080/21528586.2012.727543

Arowolo, D. 2010. The Effects of Western Civilization and Culture on Africa. Afro Asian Journal of Social Sciences 1,1: 1-13.

Brankovic, J., L. Ringel \& T. Werron 2018. How Ranking Produce Competition: The Case of Global University Rankings. Zeitschrift Fur Soziologie 47,4: 270 - 288. https://doi.org/10.1515/zfsoz-2018-0118

Chopra, M. 2004. Globalization, Urbanization and Nutritional Changes in South Africa. Journal of Development and Agricultural Economics 1,2: $220-241$.

Connell, R. 2007. Southern Theory: The Global Dynamics of Knowledge in Social Science. Sydney, NSW, Australia: Allen \& Unwin.

Connell, R. 2013. Using Southern Theory: Decolonizing Social Thought in Theory, Research and Application. Planning Theory 13,2: 210 - 223.

https://doi.org/10.1177/1473095213499216

Danermark, B., M. Ekström, L. Jakobsen \& J.Ch. Karlsson 2002. Explaining Society: Critical Realism in the Social Sciences. London: Routledge.

Daramola I. \& B. Oyinade 2015. Impact of Cultural Globalization on Africa the Role of Western Media. International Journal of Education and Research 3,3: 31-46.

Dhaouadi, M. 1990. Ibn Khaldun: The Founding Father of Eastern Sociology.

International Sociology 5: $319-335$.

https://doi.org/10.1177/026858090005003007

Encyclopaedia Britannica 2018. The Coca-Cola Company.

https://www.britanica.com/topic/The-Coca-Cola-Company 
Gbenga S. Adejare, Olayinka Akanle \& Vera E. Abaimu

(Accessed 19 March 2020).

Ezenweke, O.E. \& L.K. Nwadialor 2013. Understanding Human Relations in African Traditional Religious Context in the Face of Globalization: Nigerian Perspectives. American International Journal of Contemporary Research 3,2: $61-70$.

Hadden, R.W. 1997. Sociological Theory: An Introduction to the Classical Tradition. Ontario: Broadview Press.

Idyorough, A.E. 2002. Sociological Analysis of Social Change in Contemporary Africa. Jos: Deka Publications.

Jones M.J. 2010. Globalization or Americanization: Implication for SubSaharan Africa. In Deng, K. (ed.): Globalization - Today, Tomorrow. Rijeca and Shanghai: InTech. http://www.intechopen.com/books/ globalization--today--tomorrow/globalization-or-americanizationimplicationfor-sub-saharan-africa. 23/03/2019

Kanu, I.A. 2013. African Identity and the Emergence of Globalization. American International Journal of Contemporary Research 3,6: 34 - 42.

Kuruk, P. 2002. Doctrine of African Customary Law and the Protection of Folklore. Bulletin 36,2: 4-32.

Lee, K., D. Yach \& A. Kamradt-Scott 2011. Globalization and Health. In Merson M., R. Black \& A. Mills (eds.): Global Public Health: Diseases, Programs, Systems and Policies. $3^{\text {rd }}$ Edition. New York: Jones and Bartlett.

Lenchner, F. 2001. 'Globalisation Issues'. The Globalisation Website, http://sociology.emory.edu/facaulty/globalization

Madukwe, C.I. \& H.N. Madukwe 2010. African Value Systems and the Impact of Westernization: A Critical Analysis. International Journal of Research in Arts and Social Sciences 2: 264 - 274.

Makinde, T. 2013. Globalization as a Constraint to Development in Africa. The Nigerian Experience, 2,2. Canadian Center of Science and Education. https://doi.org/10.5539/par.v2n2p191

McMillan, M., D. Rodrik \& N. Verduzco-Gallo 2014. Globalization, Structural Change, and Productivity Growth, with an Update on Africa. World Development 63: $11-32$.

http://dx.doi.org/10.1016/j.worlddev.2013.10.012. 19/03/2019;

https://doi.org/10.1016/j.worlddev.2013.10.012

Mohan, G. \& A.B. Zack-Williams 2002. Globalization from Below:

Conceptualizing the Role of the African Diasporas in Africa's 
Development. Review of African Political Economy 29,92: 211 - 236.

https://doi.org/10.1080/03056240208704610

Olutayo, A.O. \& O. Akanle 2009. Aso-Oke (Yoruba's handwoven textiles.)

Usage among the Youths in Lagos, Southwestern Nigeria. International Journal of Sociology and Anthropology 1,3: 062 - 069.

Olutayo, A.O. \& O. Akanle 2009. Fast Food in Ibadan: An Emerging Consumption Pattern. Africa 79,2: 207 - 227.

https://doi.org/10.3366/E0001972009000692

Omobowale, A.O. \& O. Akanlez 2017. Asuwada Epistemology and Globalised

Sociology: Challenges of the South. Sociology 51,1: $43-59$.

https://doi.org/10.1177/0038038516656994

Oni, K.J. 2015. Globalization and National Development: The Nigerian

Experience. Public Administration and Management 3,7: 82 - 91.

Onyango, P. 2013. African Customary Law: An Introduction. African Books

Collective.

http://www.academia.edu/10451505/INTRODUCTION TO AFRICAN CUSTOMARY LAW

Oxford University Press 2017. Glocalisation.

https://en.oxforddictionaries.com/definition/glocalization

(Accessed 12 March 2019).

Pekarskiene, I. \& R. Susniene 2014. The Assessment of the Manifestation of Economic Globalization: The International Trade Factor. Proceedings of the $19^{\text {th }}$ International Scientific Conference; Economics and Management (ICEM), Riga, Latvia. https://doi.org/10.1016/j.sbspro.2014.11.209

Pekarskiene, I. \& R. Susniene 2015. Features of Foreign Direct Investment in the Context of Globalization. Proceedings of the $20^{\text {th }}$ International Scientific Conference Economics and Management (ICEM). ProcediaSocial and Behavioral Sciences 213: $204-210$.

https://doi.org/10.1016/j.sbspro.2015.11.427

Ritzer, G. \& J. Stepnisky 2014. Sociological Theory. New York: McGraw Hill. Surugiu M.R. \& C. Surugiu 2015. International Trade, Globalization and Economic Interdependence between European Countries: Implications for Businesses and Marketing Framework. Procedia - Economics and Finance 32: 131 - 138. https://doi.org/10.1016/S2212-5671(15)01374-X Tebeje, A. 2016. Brain Drain and Capacity Building in Africa. International Development Research Centre (IDRC). www.idrc.ca/en/article/brain-drain-and-capacity-building-africa 
Gbenga S. Adejare, Olayinka Akanle \& Vera E. Abaimu

(Accessed 27 June 2018)

Ugbam, C., B. Chukwu \& A. Ogbo 2014. The Effects of Globalization on African Culture: The Nigerian Perspective. IOSR Journal of Business and Management 16,4: 62 - 71. https://doi.org/10.9790/487X-16416271

United Nations (UN) 2020. World Economic Prospect 2020. New York.

Wedlin, L. 2014. How Global Comparisons Matter: The 'Truths' of International Rankings. Band 87. In Blockmans, W., L. Engwall \& D. Weaire (Hrsg): Bibliometrics: Use and Abuse in the Review of Research Performance. Portland, OR: Portland Press Limited.

Zahid, G. 2015. Globalization, Nationalization and Rationalization. Procedia - Social and Behavioural Science 174: 109 - 114.

https://doi.org/10.1016/j.sbspro.2015.01.633

Zoran, S. 2008. Globalization: Theoretical Perspectives, Impacts and Institutional Response of The Economy. Economic and Organization 5,3: 263 -272 .

Gbenga S. Adejare, Department of Sociology, Faculty of The Social Sciences,

University of Ibadan

Nigeria

Jare2k@yahoo.com OR

liftedjare@gmail.com

Olayinka Akanle Research Associate, Department of Sociology,

Faculty of Humanities, University of Johannesburg, South Africa And

Department of Sociology, Faculty of The Social Sciences,

University of Ibadan, Nigeria

yakanle@yahoo.com, OR olayinkaakanle75@gmail.com 
Vera E. Abaimu Department of Sociology Faculty of The Sociology University of Ibadan Nigeria vera4omolara@gmail.com 